Supporting Information

\title{
Development of a cryoprotective formula based on the fucose-containing polysaccharide FucoPol
}

Bruno M. Guerreiro ${ }^{a, b, c}$, Jorge C. Silva ${ }^{b}$,Cristiana A. V. Torres ${ }^{a}$, Vitor D. Alves ${ }^{d}$, João C. Lima ${ }^{c}$, Maria A. M. Reis ${ }^{a}$, Filomena Freitas ${ }^{a *}$

${ }^{a}$ UCIBIO-REQUIMTE, Chemistry Department, Faculty of Sciences and Technology, Nova University of Lisbon, Portugal

${ }^{\mathrm{b}}$ CENIMAT/I3N, Physics Department, Faculty of Sciences and Technology, Nova University of Lisbon, Portugal

${ }^{c}$ LAQV-REQUIMTE, Chemistry Department, Faculty of Sciences and Technology, Nova University of Lisbon, Portugal

${ }^{d}$ LEAF - Linking Landscape, Environment, Agriculture and Food, Instituto Superior de Agronomia, Universidade de Lisboa, Tapada da Ajuda, 1349-017 Lisboa, Portugal
Authors
Bruno M. Guerreiro
| Email: bm.guerreiro@campus.fct.unl.pt
Jorge C. Silva
| Email: jcs@fct.unl.pt
Cristiana A. V. Torres
| Email: c.torres@fct.unl.pt
Vítor D. Alves
| Email: vitoralves@isa.ulisboa.pt
João C. Lima
| Email: lima@fct.unl.pt
Maria A. M. Reis
| Email: amr@ffct.unl.pt 
* corresponding author

Prof. Filomena Freitas:

Faculty of Sciences and Technology, NOVA University of Lisbon

Campus de Caparica

2829-516 Caparica, Portugal

Phone number: 212948300 (ext: 10947); Email: a4406@ffct.unl.pt

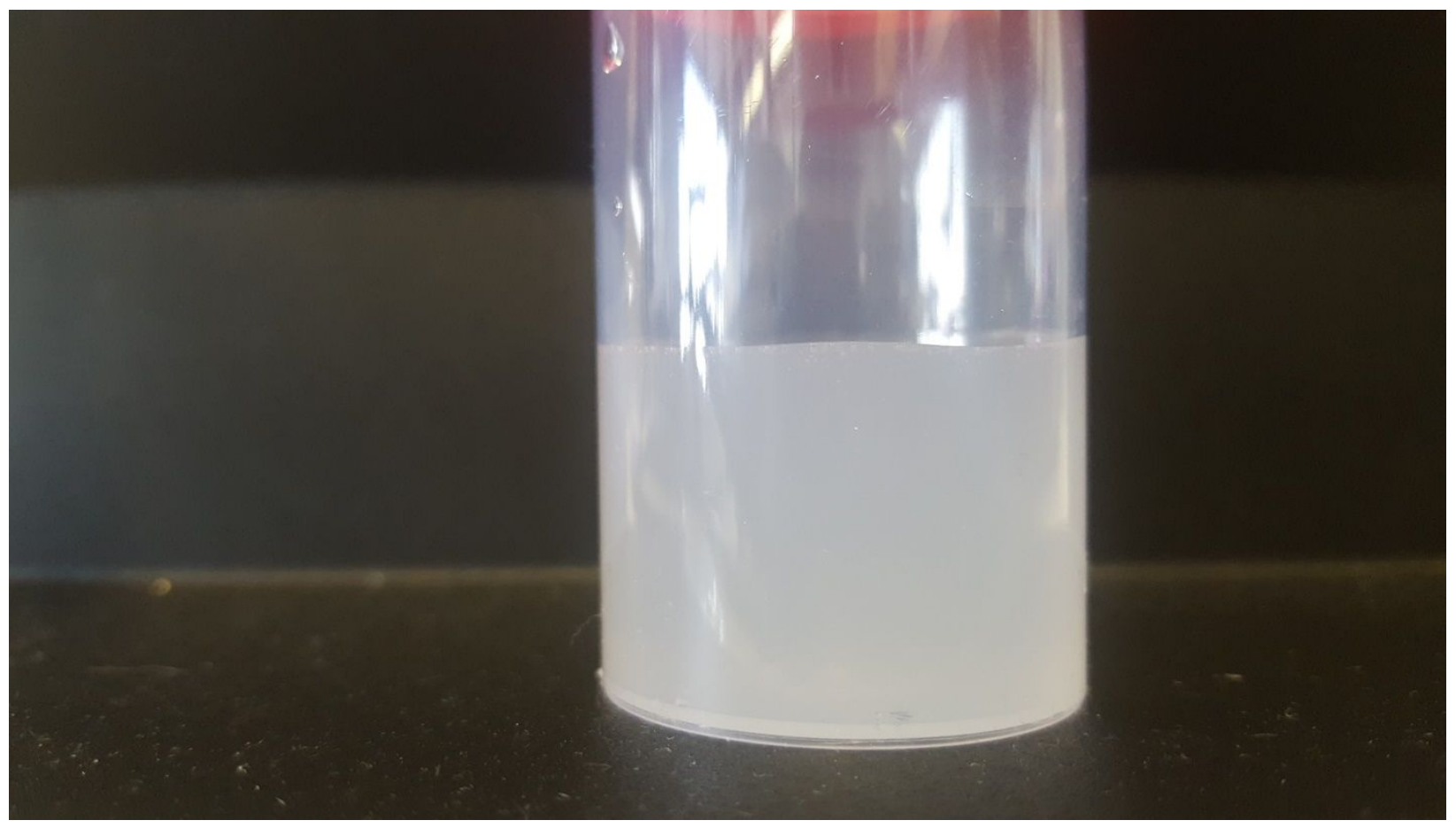

Figure S1. The visual appearance of a $0.25 \%$ FucoPol aqueous solution. 


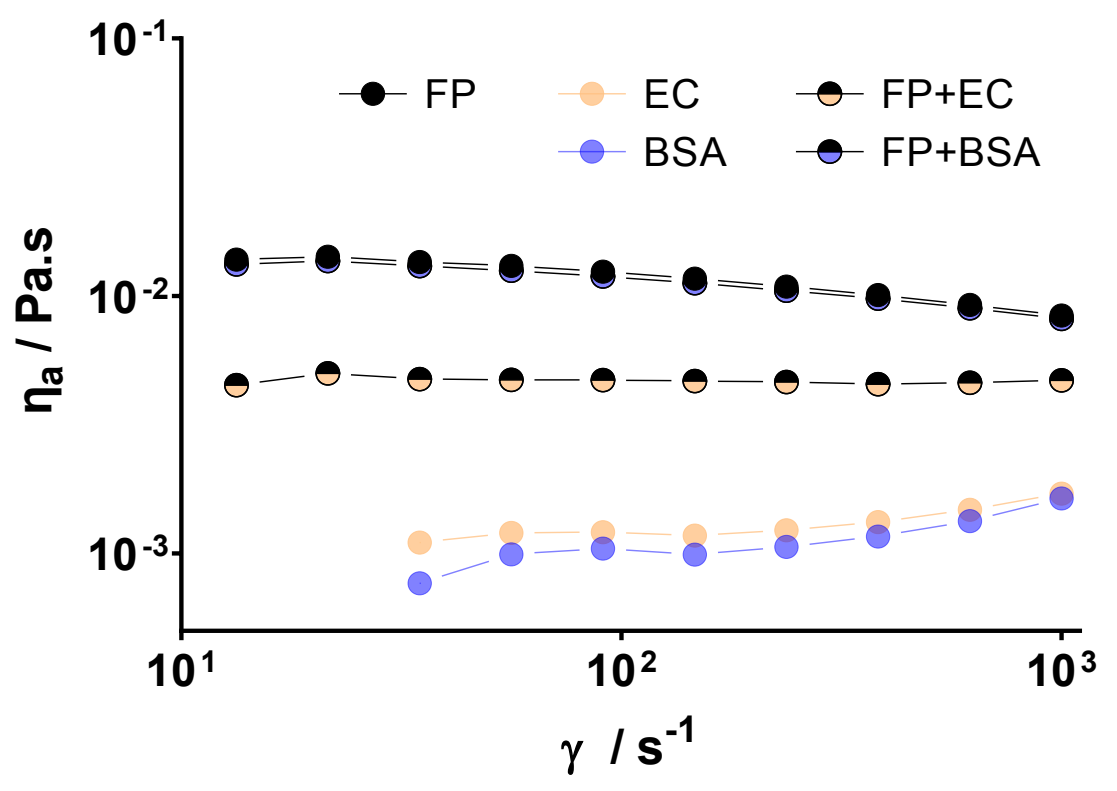

Figure S2. Flow curves obtained at $20^{\circ} \mathrm{C}$ for FucoPol aqueous solution (FP, $0.25 \%$, w/v), FucoPol $(0.25 \% \mathrm{w} / \mathrm{v})$ dissolved in a BSA $(1 \mathrm{mg} / \mathrm{ml})$ aqueous solution $(\mathbf{F P}+\mathbf{B S A})$, FucoPol $(0.25 \%$, w/v) dissolved in 1X Euro-Collins (FP+EC) and the respective BSA and Euro-Collins (EC) controls. 


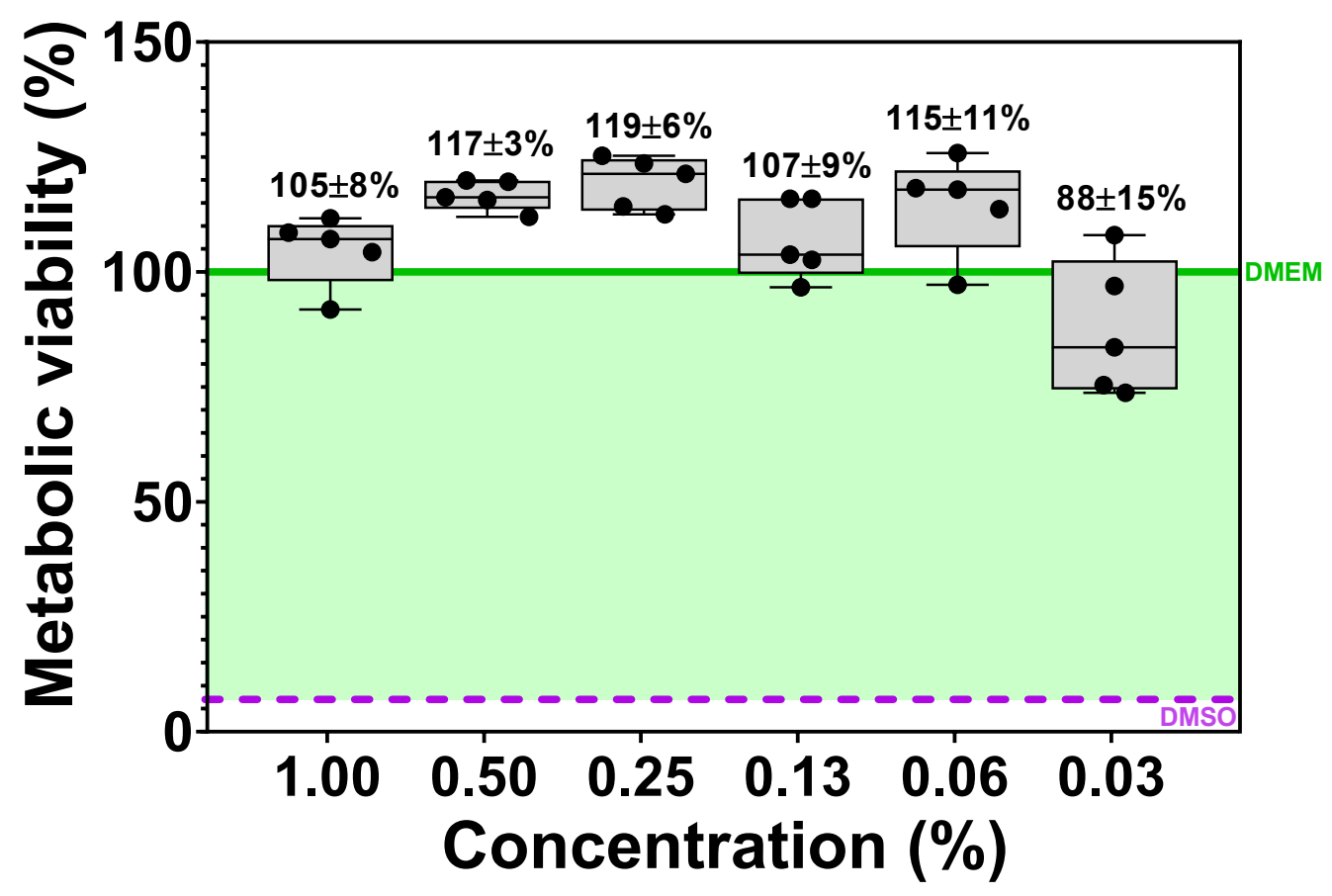

Figure S3. Metabolic viability of Vero cells as a function of FucoPol concentration, assayed by the resazurin redox reaction. Statistically, cell viability shows concentration independence. All concentrations lie above the $70 \%$ viability benchmark. 
Table S1. Ionic compositions and glucose content of the normothermic formulations used.

\begin{tabular}{cccccc} 
Concentration $(\mathbf{m M})$ & Dulbecco (+) & Dulbecco (-) & Earle & Hank & S-MEM \\
\hline $\mathbf{N a}^{+}$ & 153.0 & 153.0 & 141.5 & 141.7 & 152.7 \\
$\mathbf{K}^{+}$ & 4.2 & 4.2 & 5.4 & 5.8 & 5.4 \\
$\mathbf{C a}^{2+}$ & 1.8 & - & 0.2 & 1.3 & - \\
$\mathbf{M g}^{2+}$ & 4.0 & - & 0.8 & 0.9 & 0.8 \\
$\mathbf{C l}^{-}$ & 143.2 & 139.6 & 120.0 & 145.9 & 121.8 \\
$\mathbf{H}_{2} \mathbf{P O}_{4}^{-}$ & 1.5 & 1.5 & 1.0 & 0.4 & 10.1 \\
$\mathbf{H P O}_{4}{ }^{2-}$ & 8.1 & 8.1 & - & 0.3 & - \\
$\mathbf{S O}_{4}{ }^{2-}$ & 4.0 & - & 0.8 & 0.4 & 0.8 \\
$\mathbf{H C O}^{-}$ & - & - & 26.2 & 4.2 & 26.2 \\
$\mathbf{G l u c o s e}^{-}$ & - & - & 5.6 & 5.6 & 5.6
\end{tabular}

